\title{
Capsule Commentary on Callon et al., Assessing Problematic Substance Use in HIV Care: Which Questions Elicit Accurate Patient Disclosures?
}

\author{
Jeffrey L. Jackson, MD MPH \\ Zablocki VAMC, Milwaukee, WI, USA. \\ J Gen Intern Med 31(10): 1214 \\ DOI: $10.1007 / \mathrm{s} 11606-016-3779-y$ \\ (c) Society of General Internal Medicine 2016
}

\begin{abstract}
A dherence is an important factor in disease management for many chronic medical illnesses. Patients who are nonadherent to antiretroviral therapy risk increased viral resistance, opportunistic infections and disease acceleration. ${ }^{1}$ Substance abuse is commonly comorbid among patients with chronic disease and is a predictor for nonadherence in HIV treatment. ${ }^{2}$ Callon and colleagues found that how providers ask questions about substance abuse impacted the accuracy of patient answers. ${ }^{3}$ In their cohort, 162 patients actively abusing substances (as identified in a post-encounter interview) were audiotaped during visits with 56 providers. While substance use questions were asked less than half the time, open-ended (How's the drinking going?") and normalizing questions ("When was the last time you used?") were $100 \%$ accurate in uncovering substance abuse, while closed-ended ("Have you used any cocaine?") or biased questions ("Have you been clean?") provided accurate answers less than half the time. The authors suggest that future research should focus on why providers fail to ask about substance use and whether universal screening of high-risk patients would be effective.

An important limitation is that the group was identified as actively using based on a post-encounter interview that used open-ended and normalizing questions. It may not be surprising that similar questions during the interview would appear very accurate. However, these findings are plausible and mirror general beliefs. There are a number of topics that patients and providers have difficulty discussing including sexual trau-
\end{abstract}

ma, intimate partner violence, substance abuse, sexual orientation, sexual functioning and mental health. General dogma is that providers should approach these topics with open-ended, normalizing questions. For example, the CDC recommends that a sexual history begin with the normalizing statement, "Just so you know, I ask these questions to all of my adult patients, regardless of age, gender, or marital status." 4 Callon's contribution to the literature is to quantify just how inaccurate patient responses will be when close-ended or leading questions are used. "You don't drink, do you?" elicits a markedly different response than "Tell me about your alcohol consumption."

Corresponding Author: Jeffrey L. Jackson, MD MPH; Zablocki VAMC, Milwaukee, WI, USA (e-mail: Jeffrey.jackson6@va.gov).

\section{Compliance with Ethical Standards:}

Conflict of interest: The author has no conflicts of interest with this article.

\section{REFERENCES}

1. Lucas GM, Griswold M, Gebo KA, Keruly J, Chaisson RE, Moore RD. Illicit drug use and HIV-1 disease progression: a longitudinal study in the era of highly active antiretroviral therapy. Am J Epidemiol. 2006;163(5):412-20.

2. Chander G, Himelhoch S, Moore RD. Substance abuse and psychiatric disorders in HIV-positive patients: epidemiology and impact on antiretroviral therapy. Drugs. 2006;66(6):769-89.

3. Callon W, Beach MC, Saha S, Chander G, Wilson IB, Laws MB, Sharp V, Cohn J, Moore R, Korthuis PT. Assessing problematic substance use in HIV care: which questions elicit accurate patient disclosures? J Gen Intern Med. 2016. doi:10.1007/s11606-016-3733-z.

4. US Department of Health and Human Services. Centers for Disease Control. A Guide to Taking a Sexual History. CDC Publication: 99-8445. https://www.cdc.gov/std/treatment/sexualhistory.pdf. Accessed 8 June 2016. 